\title{
RELAÇÃO DO SUBSTRATO LITOLÓGICO COM OS PROCESSOS EROSIVOS NO MUNICÍPIO DE CACEQUI, RIO GRANDE DO SUL
}

\author{
Lucas Krein Rademann ${ }^{(a)}$, Romario Tretin ${ }^{(b)}$, Luís Eduardo de Souza Robaina ${ }^{(\mathrm{c})}$ \\ (a) Departamento de Geociências/ Universidade Federal de Santa Maria, E-mail: lucasrademann@yahoo.com; \\ (b) Departamento de Geociências/ Universidade Federal de Santa Maria, E-mail: romario.trentin@ gmail.com \\ ${ }^{(c)}$ Departamento de Geociências/ Universidade Federal de Santa Maria, E-mail: lesrobaina @ yahoo.com.br
}

\section{Eixo: 10. SISTEMAS GEOMORFOLÓGICOS: ESTRUTURAS, DINÂMICAS E PROCESSOS}

\begin{abstract}
Resumo
Os processos erosivos são importantes temas de estudo frente às análises ambientais, pois implicam na capacidade produtiva do solo e suas transformações ambientais e sociais, desta forma, torna-se de grande importância sua análise para fins de planejamento e manejo de uma área. Portanto, este trabalho tem como objetivo o mapeamento de feições erosivas no município de Cacequi-RS e a sua relação com a litologia da área de estudo. As feições erosivas foram digitalizadas manualmente com interpretação visual sobre imagens de satélite nos softwares ArcGis e Qgis, além de serem utilizados dados da CPRM para os estudos da litologia do município. Em seguida, foi feita uma análise descritiva e comparativa dos resultados encontrados entre processos e dados litológicos do município. Observou-se que os processos erosivos no município de Cacequi estão relacionados às litologias arenosas e de baixa cimentação, caracterizadas por Arenitos Eólicos e Arenitos Micáceos.
\end{abstract}

Palavras-Chave: Erosão, Litologia, Cacequi-RS

\section{Introdução}

Os estudos sobre processos erosivos têm recebido destaque nas últimas décadas, pois geram impacto econômico para atividade agrícola, causando perda de solo e de fertilidade, como salientam Maciel Filho e Nummer (2011) "a erosão tem como efeito imediato a perda de camadas de solo fértil, acarretando menores produções agrícolas e consequente desvalorização".

Guerra (1993) define erosão como o trabalho mecânico de destruição exercido pelas águas correntes, carregadas de sedimentos, destruindo as saliências ou reentrâncias do relevo, tendendo a um nivelamento ou colmatagem. Ou seja, caracteriza-se o processo superficial como a desagregação e o transporte de material do solo.

A região Oeste do Rio Grande do Sul possui muitas áreas suscetíveis a processos erosivos devido às características fisiografias de rocha e solo muito friáveis com textura areno-siltosa e estrutura mal desenvolvida.

Robaina e Trentin (2004) ainda destacam que a degradação dos solos associada a processos erosivos avançados, no oeste do estado do Rio Grande do Sul, pode ser considerado um dos mais importantes problemas ambientais dos nossos dias. 
XVII Simpósio Brasileiro

de Geografia Fisica Aplicada

I Congresso Nacional

de Geografia Física

\section{OS DESAFIOS DA GEOGRAFIA FÍSICA NA FRONTEIRA DO CONHECIMENTO \\ Instituto de Geociências - Unicamp \\ Campinas - SP \\ 28 de Junho à 02 de Julho de 2017}

Portanto, este trabalho tem como objetivo o mapeamento das feições erosivas lineares no município de Cacequi, tais como sulcos, ravinas e voçorocas, através de ferramentas de geoprocessamento, e a sua relação com a litologia da área de estudo.

\section{Metodologia}

Cacequi que está localizado na região Oeste do Rio Grande do Sul e tem seus limites com os municípios de Alegrete, São Vicente do Sul, São Pedro do Sul e Rosário do Sul, como representado no mapa da Figura 1.

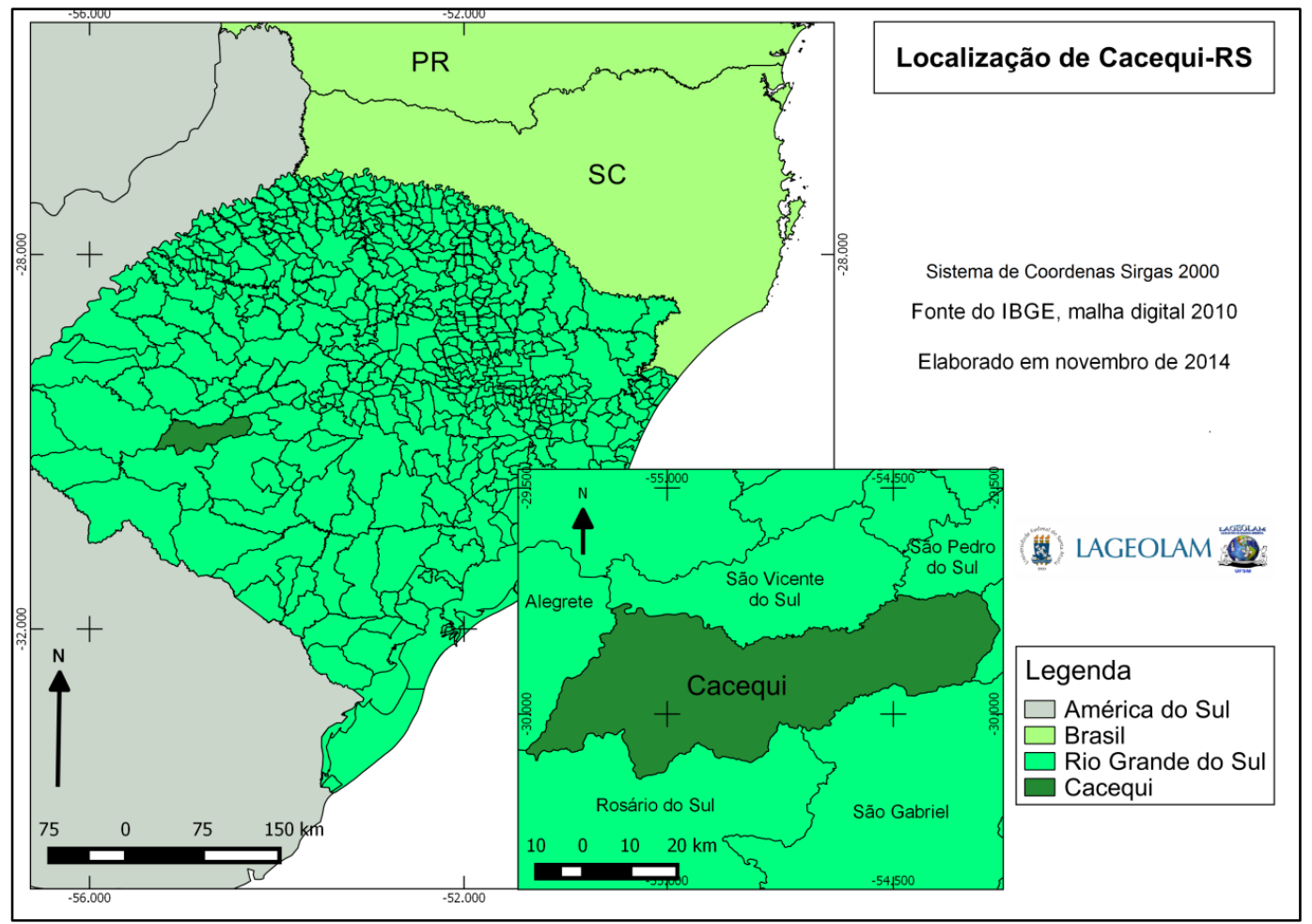

Figura 1 - Mapa de Localização do Município de Cacequi, RS;

Para a identificação das feições foram usadas imagens de satélite QuickBird datadas do ano de 2008 disponíveis através do software Google Earth Pro ${ }^{\circledR}$. As feições erosivas foram digitalizadas manualmente com interpretação visual sobre a imagem, nos softwares ArcGis, desenvolvido pela ESRI e Qgis, software livre, considerando feições erosivas, todo processo de dinâmica superficial associado à sulcos, ravinas e voçorocas, que segundo IPT (1990) sulcos constituem feições alongadas e rasas (inferiores a $50 \mathrm{~cm}$ ); as ravinas são feições de maior porte, de profundidade variável, de forma alongada e não atingem o lençol de água subterrânea e as voçorocas tem dimensões superiores às ravinas e atingem o lençol de água subterrânea, havendo portanto processo de erosão subterrânea (piping).

Para as análises da litologia do município, foram utilizados como base, os dados da Wildner et al., (2006) que apresenta o mapeamento geológico do estado do Rio Grande do Sul. Estes dados foram 
detalhados através de trabalhos de campo com descrição de rochas e solos, coletas de amostras ao longo de toda a área do município, percorrendo as estradas e caminhos. Ao todo foram discriminadas quatro classes de litologia, os Arenitos Eólicos, pertencentes à Formação Pirambóia (Wildner et al. 2006), Arenitos Fluviais com grânulos silicosos, pertencentes à Formação Guará, Arenitos Fluviais com mica da Formação Sanga do Cabral, e também Depósitos Aluviais Atuais e Colúvios.

Após o levantamento dos dados do município foi utilizado a ferramenta spatial join para relacionar com os dados de processos do município de Cacequi. Estes dados foram editados no ArcGis 10.1 e posteriormente trabalhados no software Excel 2010.

Depois do levantamento dos dados foi feita uma análise descritiva e comparativa dos resultados encontrados dos processos com os dados litológicos do município.

\section{Resultados}

Cacequi possui um solo arenoso e bastante suscetível á ocorrências de erosão, desta forma, foram mapeadas 2.978 feições erosivas em sua área total de 2.338,64 km² e estas distribuídas em todo o município como se pode observar na Figura 2.

$\mathrm{Na}$ área de estudo se apresentam quatro tipos distintos de litologias representadas por: Arenitos Eólicos (40,01\%), Depósitos Aluviais Atuais e Colúvios (36,72\%), Arenitos Fluviais com Mica $(14,91 \%)$ e Arenitos Fluviais com Grânulos Silicosos (7,97\%).

As feições erosivas se apresentam em maior quantidade nos locais de afloramento litológico de Arenitos Eólicos, cerca de 67\%, por serem bastante friáveis, com relativamente, menor número de ligantes na rocha. Outros $23 \%$ das feições erosivas se apresentam sobre a litologia de Arenitos Fluviais com Micas que, também, são friáveis, mas a presença de camadas finas pode limitar o aprofundamento da erosão. Os 10\% restantes estão concentrados sobre Arenitos Fluviais com Grânulos Silicosos que é uma litologia um pouco mais resistente aos processos erosivos lineares pela ocorrência de óxido de ferro como ligante e, portanto, apresentando menor quantidade de feições. 


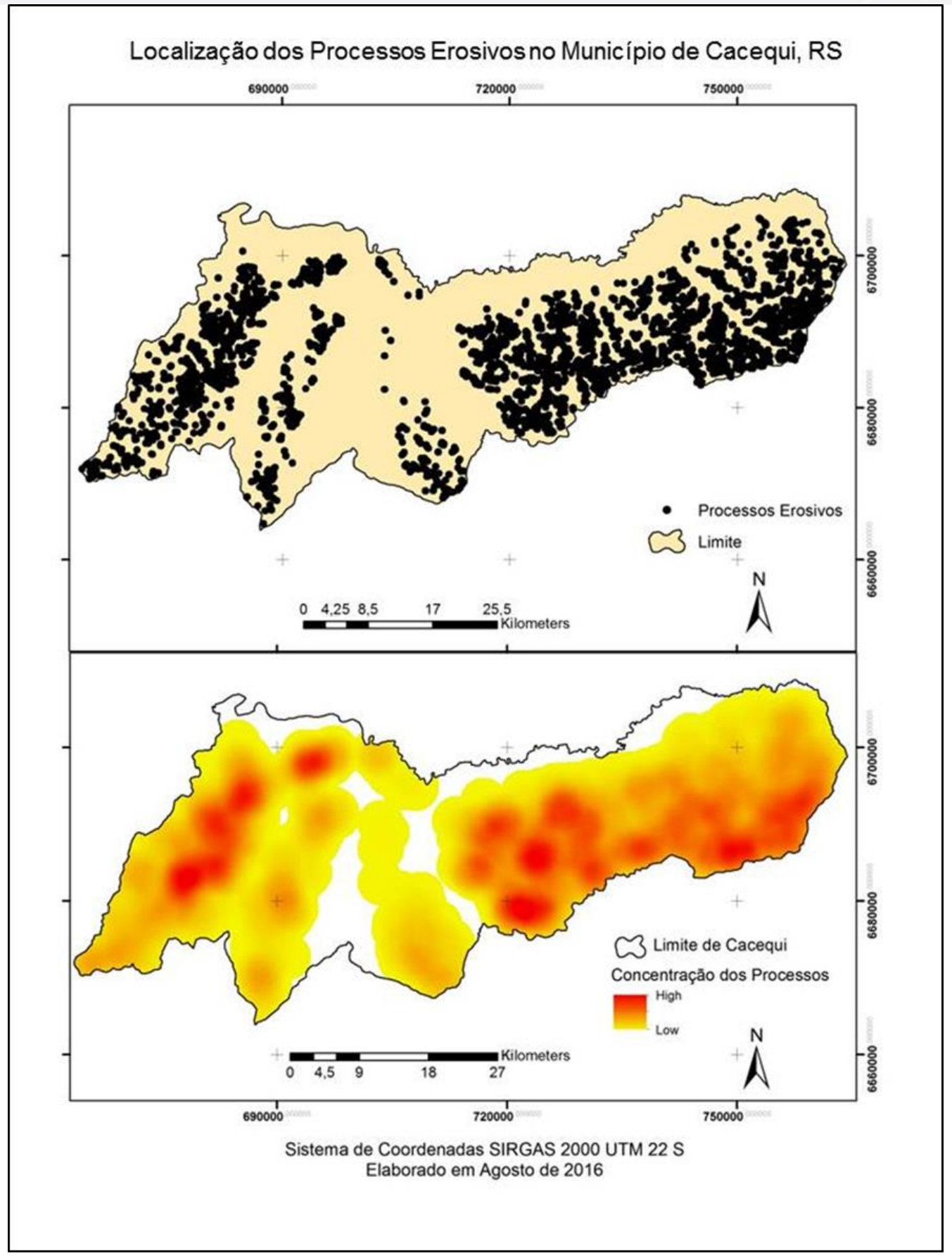

Figura 2 - Mapa da Localização das Feições Erosivas no município de Cacequi, RS;

Quanto a concentração das feições erosivas nas litologias, podemos destacar que nas litologias de arenito eólico há uma concentração elevada destas por $\mathrm{km}^{2}$ com um valor de 2,18, como representado na Figura 3. Já nas áreas com arenitos fluviais com mica a concentração é de 2,06 feições por km². 


\begin{tabular}{|c|c|c|c|}
\hline Classe & Área(km $\left.\mathbf{k}^{\mathbf{}}\right)$ & Feições & Índice \\
\hline Arenito Eólico & 943,61 & 2060 & 2,18 \\
\hline Arenito fluvial Com Grânulos Silicosos & 186,11 & 299 & 1,61 \\
\hline Arenito Fluvial Com Micas & 348,31 & 716 & 2,06 \\
\hline Depósitos Aluviais e Colúvios & 857,71 & 0 & 0,00 \\
\hline
\end{tabular}

Figura 3 - Tabela da Concentração de Processos Erosivos nas Litologias de Cacequi/RS;

\section{Considerações Finais}

Observou-se durante o estudo que as feições erosivas em Cacequi estão bastante relacionadas aos fatores de litologia, sendo a classe com maior número de processos erosivos lineares a classe de Arenito Eólico, que está relacionado a litologias frágeis, muito friáveis, concentrado nas porções Central e Oeste do município. Outra classe que apresenta grande índice de feições por metro quadrado é a de Arenitos com Mica, que apresenta um valor de 2,06 feições $/ \mathrm{km}^{2}$, representando sua susceptibilidade à erosão.

De modo geral as ferramentas de geoprocessamento se mostraram eficientes para a análise da litologia de Cacequi, para a identificação e mapeamento das feições erosivas e posteriormente para a análise dos dados obtidos, se dando de forma rápida e eficiente. Visto que a erosão dos solos são indicadores de degradação ambiental do solo, o trabalho se mostrou importante para futuros estudos geoambientais e também para a mitigação dos problemas de erosão encontrados em Cacequi.

\section{Referências}

GUERRA, A. T. Dicionário Geológico Geomorfológico, 8ed, Rio de Janeiro: IBGE, 1993.

MACIEL FILHO, C. L.; NUMMER, A. V. Introdução à Geologia de Engenharia. 4 ed., Santa Maria: Editora da UFSM, 2011.

ROBAINA, L. E. S.; TRENTIN, R. Degradação dos solos: Problema ambiental no Sudoeste Gaúcho. Interface v.1, 29-41, 2004.

WILDNER, W. et al. Mapa Geológico do Estado do Rio Grande do Sul - Escala 1:750000. Porto Alegre CPRM, Serviço Geológico do Brasil, 2006.

SÃO PAULO, Secretaria de Energia e Saneamento. Departamento de águas e energia elétrica, controle de erosão. Bases conceituais e técnicas, diretrizes para o planejamento urbano e regional orientações para o controle de boçorocas urbanas. São Paulo, DAEE/IPT,1990, 2ª edição. 